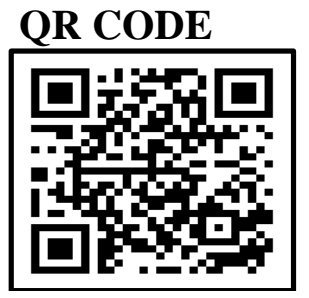

\title{
5-HT3 Antagonist for Pregnancy Associated Nausea and Vomiting
}

\author{
SUMIT GHOSH ${ }^{1}$, NIRANKAR DEV ${ }^{2}$, DAVID MATTHEWS 3
}

5-HT3 antagonists appear to be an effective treatment option in the treatment of nausea and vomiting associated with pregnancy. Literature suggests an increased risk of congenital defects in fetuses exposed to ondansetron during pregnancy, especially during first trimester. Health authorities now suggest that this drug should not be used during this period. However, this decision is debatable and whether ondansetron can be used in pregnant women is still controversial.

KEYWORDS: Pregnancy, Nausea, Vomiting

\section{INTRODUCTION}

Nausea and vomiting of pregnancy are among the most frequently reported functional disorders in pregnant women., ${ }^{1,2}$ These disorders usually appear between week six and week nine of pregnancy, with a peak around week 11, and generally disappear at the end of the first trimester of pregnancy. Usually benign and classified among what are informally known as the minor ailments of pregnancy, they can, however, be disabling, and have a significant impact on women's quality of life. ${ }^{3}$ They must then be thoroughly investigated in order to rule out an underlying condition, and it may be desirable, in these situations, to offer women appropriate pharmacological management. In some countries, there is no recommendation for clinical practice in relation to the management of nausea and vomiting in pregnancy, but there are such recommendations in other countries..$^{-6}$ Of the recommended therapeutic strategies, ondansetron, proposed as second-line treatment in severe nausea and vomiting of pregnancy, has been shown to be effective. Although it is little prescribed during pregnancy in few nations, it is, conversely, widely used in the United States with, according to studies, between 5 and $10 \%$ of women exposed to it during pregnancy..$^{-}$ 9 In November 2019, the European Medicines Agency stated that this drug must not be used during the first trimester of pregnancy as it might lead to an increased risk of oral clefts, and increased risk of cardiac malformations. ${ }^{10}$

The published data relating to the possibility that ondansetron is teratogenic are relatively numerous and disparate in terms of methodological quality. A recently published meta-analysis, concluded that there was no significant association between exposure to ondansetron in the first trimester and an increased overall risk of major malformations. However, it highlighted a slight increase in the risk of oral clefts and cardiac malformations such as ventricular septal defects." The meta-analysis notably included the two publications which directed the recent position of the EMA.9,12 In one, results were drawn from a cohort of more than 1.8 million Medicaid-enrolled pregnant women in the USA between 2000 and 2013, 88,467 of whom had been exposed to ondansetron in the first trimester of pregnancy and had given birth to a live child. ${ }^{9}$ Well conducted from a methodological point of view and based on a large population sample, with the standard exclusion of pregnancies exposed to known teratogenic agents and children with chromosome abnormalities and considering a large number of potential confounding factors by using propensity scores, the authors found no increase in the overall risk of major malformations in the event of exposure to ondansetron in the first trimester of pregnancy.

Another study included a little over 860,ooo motherchild pairs between 2000 and 2014. ${ }^{12}$ The children involved were born alive, with no chromosome abnormalities, and the women had no family history of malformations and had not received any antiemetic other than ondansetron. Some studies have focused on the possible teratogenic effect of ondansetron. These included a monocentric

(C) Sumit Ghosh et al. This is an open access article distributed under the terms of the Creative Commons Attribution License CC-BY-NC 4.o, which permits unrestricted use, distribution and reproduction in any medium, provided the use is not commercial and the original author(s) and source are cited. Submitted on: 16-Nov-2021; Accepted on: 13-Dec-2021 
retrospective cohort study which found an increased risk of ventricular septal defects in neonates exposed to ondansetron in the first trimester. ${ }^{13}$

It should be noted that these were cardiac abnormalities noted at birth, and no account was taken of the severity and spontaneous course of these ventricular septal defects. In 2020, a complementary analysis was conducted, restricted to women who had received intravenous ondansetron in the first trimester: no association was highlighted, either for the overall risk of a major malformation, for heart malformations, or for orofacial clefts. ${ }^{14}$ The last two studies did not highlight an increased risk of malformation in relation to exposure to ondansetron in the first trimester. ${ }^{15,16}$ To summarize this bibliographic analysis, although an increased risk of orofacial clefts cannot be formally ruled out in the event of exposure to ondansetron in the first trimester of pregnancy, if it exists it appears to be a very low risk, with a prevalence of around $0.11 \%$ in fetuses exposed in utero, compared to $0.08 \%$ in the general population. With regard to congenital heart disease and an increased risk of ventricular septal defects, the methodological limitations of the currently available studies mean that it is impossible to maintain that there is an increase in this risk.

On the basis of these data, the recommendations which lead to ondansetron being formally excluded from the therapeutic strategy of severe pregnancyinduced vomiting in the first trimester of pregnancy do not seem appropriate. Furthermore, this opinion is also shared by other experts in pre- and postnatal vigilance who are members of the European Network of Teratology Information Services. ${ }^{17}$

In practice, it seems reasonable to consider prescribing ondansetron to a pregnant woman with severe pregnancy-induced vomiting if first-line treatments, such as doxylamine alone or in combination with vitamin B6 or metoclopramide, have failed, and especially after week ten of pregnancy. ${ }^{18}$ Although it may be preferable not to use ondansetron before week ten, as a precautionary measure, exposure before this time should, nevertheless, not lead to the patient being worried: at most, good-quality ultrasound monitoring of the fetus targeted at the facial mass may be considered in principle. In order to best specify any potential risk this drug carries during pregnancy, and thus to better inform healthcare professionals and pregnant women, it is important to regularly update the state of knowledge on this drug and pregnancy in the light of new publications..$^{8}$ Ondansetron is a serotonin 5$\mathrm{HT}_{3}$ receptor antagonist, this receptor being involved in emetic reflex phenomena. It is indicated in the prevention of postoperative or chemotherapyinduced vomiting. Although its efficacy in nausea and vomiting in pregnancy has been proven, it does not as yet have a marketing authorization in this indication.

On the basis of the efficacy data and safety data, the preferred first-line treatments are either doxylamine, alone or in combination with vitamin B6 or metoclopramide. If these options are not suitable, the use of ondansetron may be envisaged if possible as a precaution after week 10. The use of this antiemetic is nevertheless very common and the data in pregnant women exposed in the first trimester of pregnancy are very numerous and reassuring. In some countries, other compounds are suggested, but their use has not always been assessed in this indication.

\section{REFERENCES}

1. Einarson TR, Piwko C, Koren G. Quantifying the global rates of nausea and vomiting of pregnancy: a meta analysis. J Popul Ther Clin Pharmacol. 2013;20(2):e171-83.

2. Lacroix R, Eason E, Melzack R. Nausea and vomiting during pregnancy: a prospective study of its frequency, intensity, and patterns of change. Am J Obstet Gynecol. 2000;182(4):931-7.

3. Tan A, Lowe S, Henry A. Nausea and vomiting of pregnancy: effects on quality of life and day-to-day function. Aust N Z J Obstet Gynaecol. 2018;58(3):27890.

4. Campbell K, Rowe H, Azzam H, Lane CA. The management of nausea and vomiting of pregnancy. $\mathrm{J}$ Obstet Gynaecol. 2016;38(12):1127-37.

5. Royal College of Obstetricians Gynaecologists. The management of nausea and vomiting of pregnancy and hyperemesis gravidarum. Green-top Guideline No.69; 2016.

6. Committee on Practice Bulletins-Obstetrics. ACOG practice bulletin No. 189: nausea and vomiting of pregnancy. Obstet Gynecol. 2018;131(1):e15-30.

7. Meyer A, Fermaut M, Drouin J, Carbonnel F, Weill

A. Drug use for gastrointestinal symptoms during pregnancy: a French nationwide study 2010-2018. PloS One 2021;16(1):e0245854.

8. Parker SE, Van Bennekom C, Anderka M, Mitchell AA, National Birth Defects Prevention Study. 
Ondansetron for treatment of nausea and vomiting of pregnancy and the risk of specific birth defects. Obstet Gynecol. 2018;132(2):385-94.

9. Huybrechts KF, Hernandez-Diaz S, Straub L, Gray KJ, Zhu Y, Patorno E, et al. Association of maternal first-trimester ondansetron use with cardiac malformations and oral clefts in offspring. JAMA 2018;320(23):2429-37.

https://doi.org/10.1001/jama.2018.18307

10. Updated Signal assessment report on birth defects following in-utero exposure during the first trimester of pregnancy arising from recent publications with ondansetron; 2019. (Online PDF). Available from: https://www.ema.europa.eu/en/documents/pracrecommendation/updated-signal-assessment-report birth-defects-following-utero-exposure-during-firsttrimester en.pdfl. [Last Accessed on $15^{\text {th }}$ August, 2021]

11. Picot C, Berard A, Grenet G, Ripoche E, Cucherat M, Cottin J. Risk of malformation after ondansetron in pregnancy: an updated systematic review and metaanalysis. Birth Defects Res 2020;112(13):996-1013. https:// doi.org/10.1002/bdr2.1705

12. Zambelli-Weiner A, Via C, Yuen M, Weiner DJ, Kirby RS. First trimester ondansetron exposure and risk of structural birth defects. Reprod Toxicol Elmsford N. 2019;83:14-20.

13. Lemon LS, Bodnar LM, Garrard W, Venkataramanan R, Platt RW, Marroquin OC, et al. Ondansetron use in the first trimester of pregnancy and the risk of neonatal ventricular septal defect. Int J Epidemiol. 2020;49(2):648-56. https://doi.org/10.1093/ije/dyz255

14. Huybrechts KF, Hernandez-Diaz S, Straub L, Gray $\mathrm{KJ}$, Zhu Y, Mogun H, et al. Intravenous ondansetron in pregnancy and risk of congenital malformations. JAMA 2020;323(4):372-4. https://doi.org/10.1001/jama.2019.18587.

15. Berard A, Sheehy O, Gorgui J, Zhao J-P, Soares de Moura C, Bernatsky S. New evidence for concern over the risk of birth defects from medications for nausea and vomiting of pregnancy. J Clin Epidemiol. 2019;116:39-48.

https://doi.org/10.1016/j.jclinepi.2019.07.014

16. Dormuth CR, Winquist B, Fisher A, Wu F, Reynier $\mathrm{P}$, Suissa $\mathrm{S}$, et al. Comparison of pregnancy outcomes of patients treated with ondansetron vs. alternative antiemetic medications in a multinational. Population-based cohort. JAMA Netw Open. 2021;4(4):e215329.

https://doi.org/10.1001/jamanetworkopen.2021.5329

17. Damkier P, Kaplan YC, Shechtman S, Diav-Citrin $\mathrm{O}$, Cassina M, Weber-Schoendorfer C, et al. Ondansetron should never be used in pregnancy: against: ondansetron in pregnancy revisited. BJOG Int J Obstet Gynaecol. 2021;128(1):111-2. https://doi.org/10.1111/1471-0528.16476

18. Vabre C, Araujo M, Damase-Michel C et al., Initial data on the safety of metopimazine during pregnancy and the risk of birth defects and pregnancy loss - An observational study using the EFEMERIS database, Therapies.

https://doi.org/10.1016/j.therap.2021.09.006. 